\title{
BRAIN AND BEHAVIOR - HYPOTHALAMUS AND LIMBIC SYSTEM: THE NEUROBIOLOGY OF EMOTIONS
}

\author{
ANJALI DAISY S* \\ Department of MBA, School of Management, SASTRA University, Thanjavur, Tamil Nadu, India. Email: anjalidaisy2011@gmail.com
}

Received: 24 April 2017, Revised and Accepted: 16 May 2017

\section{ABSTRACT}

It is intuitive to understand how sensory information gets to the brain and how motor information can travel to the muscles together where these two systems allow us to detect and respond to the world around us but how do we engage with that world, how do we determine what is important, and how do we fall in the analysis. These higher cortical functions involve the complex interplay between neurotransmitters and hormones throughout the entire nervous system. There are two major anatomical behaviors; the limbic system and hypothalamus. These structures that support much higher cortical functions hypothalamus is a very small structure but it is absolutely critical for life and it allows us to respond to both the internal and external environment and to maintain homeostasis. The limbic system is important for learning and memory, and all emotional aspects of behavior importantly limbic and hypothalamic structures are interconnected with each other. Let's begin with an anatomical overview of the hypothalamus in the middle section. You can delineate the hypothalamus from the thalamus through the hypothalamic sulcus anteriorly, the hypothalamus extends to the anterior commissure, and the optic chiasm inferiorly and it includes the mammillary bodies and extends to the infundibula stock where it communicates with the pituitary glands. It is a coronal section through the brain. It is the third ventricle, you can identify the thalamus on either side of the third ventricle and underneath; the thalamus is the hypothalamus and it extends laterally to these descending fiber bundles which are part of the internal capsule. The hypothalamus is structurally part of the diencephalon but it functions as part of the limbic system through reciprocal connections. It helps to maintain homeostasis in the entire body through influences on the endocrine system and importantly through its primary influence on both the sympathetic and parasympathetic systems; the limbic system is extremely old from an evolutionary perspective in its connections and it is interposed between the hypothalamus and the neocortex and providing a bridge between endocrine visceral emotional and voluntary responses to the environment.

Keywords: Hypothalamus, Emotions, Amygdala, Post dramatic stress disorder.

(C) 2017 The Authors. Published by Innovare Academic Sciences Pvt Ltd. This is an open access article under the CC BY license (http://creativecommons. org/licenses/by/4. 0/) DOI: http://dx.doi.org/10.22159/ajpcr.2017.v10i8.19372

\section{INTRODUCTION}

We know that widespread areas of the central nervous system are part of it processing; however, here we will focus on the core limbic structures that these structures include deep for brain nuclei and cortical areas $[1,2]$. The key cortical area is the limbic lobe, it is not a true lobe rather, it spans the frontal parietal and temporal lobes, and it comprises arraign of cortex on the medial surface of the brain the finger Lager is and the parahippocampal gyrus [3-7]. It is the anterior swelling of the parahippocampal gyrus is the incus. The hippocampus is primarily involved in memory, and the amygdala is primarily responsible for emotional processing [8].

Fig. 1 conveys that in its specimen we have opened the lateral ventricle to show you the hippocampus as it lies on the floor of the inferior horn. It bulges here is the hippocampus toward the posterior end fibers emerging that will form the fornix and will swing over the thalamus to reach the mammillary bodies of the hypothalamus [9]. In it the specimen, we have approached the hippocampus from a medial approach and we have taken away part of the temporal cortex here the lateral ventricle is right here and lying on the floor of the lateral ventricle is the hippocampus. It is unusual view of the hippocampus which shows the underside of its structure and exemplifies the increased surface area achieved through extensive folding here's the outflow from the hippocampus the fornix [10-13]. These fibers swing around the thalamus and come down here as the columns of the fornix just posterior to the anterior commissure; the columns of the fornix will project down to the mammillary bodies and the mammal economic track is going to connect the mammillary bodies with the anterior nucleus $[4,13,14]$ and the dorsal medial nucleus of the thalamus from the thalamus the information travels to the limbic lobe [15-17].

\section{VOYAGE BETWEEN BRAIN AND EMOTION}

It is the classic PAPA Circuits involved in learning memory and emotion now knows that many other structures are involved in it [18]. A circuit including the amygdala is located in the roof of the inferior horn of the lateral ventricle directly underneath the uncus. The uncus is the anterior extension of the parahippocampal gyrus and it is easily identifiable through its hook-like appearance directly underneath the uncus lies the amygdala. Let's take a look at a cross-section through its area [19]. It is a coronal section through the forebrain corpus callosum that is the

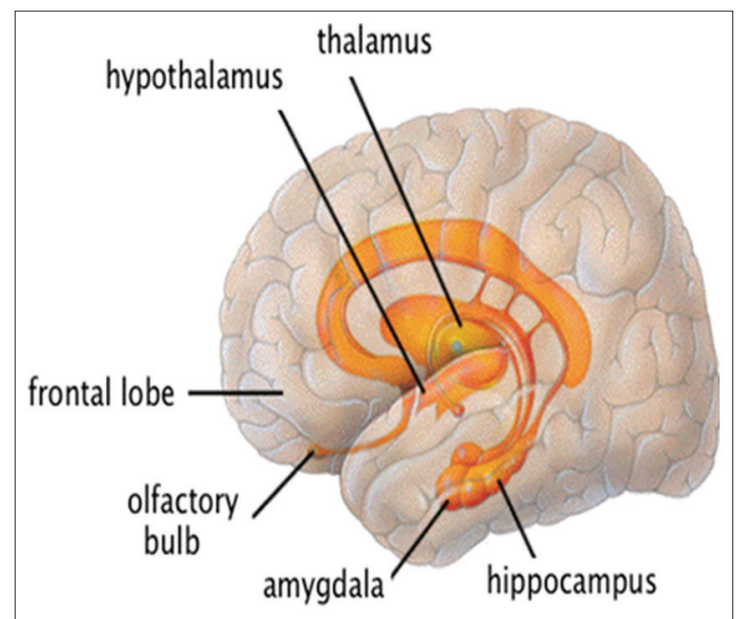

Fig. 1: Functioning of brain 
anterior horn of the lateral ventricle and inferior horn of the lateral ventricle and here in the floor of the inferior horn hippocampus right here its different layers of neurons give it that striped appearance when we turn it section around [20]. We are now more anterior and we can see the amygdala, it lies superior and anterior to the hippocampus [21]. It stretches of cortex here is the incus. The amygdala is a key structure in the expression of emotion emotional memory and basic drives let's get oriented to diagram. It is the lateral ventricle. It is the anterior horn the posterior horn and it year is the inferior horn which lies deep within the temporal lobe is the thalamus, hippocampus, and the fornix [22]. The hypothalamus with the mammillary body let's trace the papa's circuit. The circuit is the bridge between emotional endocrine visceral and voluntary responses to the environment from the hippocampus a fiber bundle emerges. It is the fornix its wings around the thalamus to converge behind the anterior commissure as the columns of the fornix the columns of the fornix project to the mammillary body from the mammillary bodies the mammal autonomic tract projects to the anterior and dorsal medial nucleus of the thalamus [23]. Modern neuroscience has established a link between the amygdala and the hypothalamus as well. It is an important connection for fear responses and salience II filtering an additional layer of integration happens within the limbic lobe. It is the basic network of connections that allows us to engage with our environment determine what's important and fall in love [24].

\section{BRAIN ENCODES FEAR}

How the brain encode sphere and how it can go awry in fear. Fear disorders and severe anxiety disorders and how the new neuroscience of understanding emotion and fear can help us to inhabit and transcend fear in our daily lives fear lives in a part of the brain called the amygdala [25]. The amygdala is about two inches inside of the years.

What is so fascinating about the amygdala and processing of fear is the same brain region as conserved across all mammals down to the lowest mice and most vertebrates and the experience that we fear the basic root of fear reflex that we have during these experiences of fear that we as humans have is not so different than that of a mouse [26] and so it is allowed us as a feed to advance our understanding of behavior specifically the neuroscience of fear more so that I would argue than almost any other neuroscience of behavior because of its conservation when we see an image that even in its most cursory way reminds us of a fearful stimulus it activates the sensory representation in the eyes and then the first way station in the brain called the thalamus [27].

The thalamus then sends its information to much higher brain cortical areas that lead to the conscious awareness of fear or the conscious awareness more specifically of the visual image but hundreds of milliseconds before we are consciously aware of it the thalamus, also its midway station sends a signal to the amygdala which activates it. The whole hard-wired reflex of fear survival responding and experience it $[7,28]$. Anxiety disorders can be considered as "intact" condition, which almost totally disturbs the routine life of the person. Creating a condition of unexplained anticipatory fear and apprehension regarding the occurrence of even normal things in life. Drug development for anxiety requires new pharmacological agents acting at specific neurotransmitters and neuropeptides, their reuptake and metabolism [29].

\section{AMYGDALA ACQUISITION WITH LIMBIC SYSTEM}

Probably most of us have had is something like walking through a park, walking through the woods, enjoying a nice pleasant day and then all of a sudden there's a snake...your hearts pounding, your chest is up and down, your breathing, and you are sweating, you have to escape and only after all that seemingly has already happened and time to slow down do you realize, it was merely a stick what has happened is that your body has activated the spider flight response before you can consciously be aware of what happened and that is going on every day and people with severe anxiety disorders and fear-related disorders, the cues of the world that activate fear are activating it [30-34].
Basic primitive reflex before you can control it. It is what your brain looks like on fear, it is a functional magnetic resonance imaging of fearful versus neutral faces, and it has been basic findings that have been replicated across the world [17]. The amygdala is hyperactivated when a fearful stimulus has occurred and what we find and it is worked by immediate stimulus across post-traumatic stress disorder (PTSD) [35]. Social anxiety disorder specific phobias; the amygdala is hyperactivated and hypersensitive. In these disorders, the root of fear of these disorders we can think of with the term a panic attack and with a panic attack, people will have an experience where their heart is racing, the chest is pounding, they cannot catch their breath or sweating, they have to get away, they feel like they're died and panic attacks happen in all of these anxiety disorders in panic disorder, it seems like the fear comes out of the blue, and in many ways, it is fear of fear itself after the first panic attack, which is often at a time of high stress or depression or trauma one will associate the experience of fear with the bodily reminders that occurred with the fear reaction [36,37], so the next time their stomach is upset or their heart is racing, they are afraid, they are going to have another attack, it becomes a fear of the fear itself the phobias if you are afraid of a spider and a big spider hands on you. You are scared to death we do not call it a panic attack but it is actually the same symptoms and similarly with trauma [32]. Parenting process is significant in endorsing and fostering the physical, emotional, social, financial, and intellectual development of children from infancy to adulthood. This process not only share the biological relationship with their children but also raise them to independent, unique personalities. This task is not an easy one; thus, stress is quite common in parenting. However, the coping pattern varies with the amount of pressure and parental ability to cope with the stressors [38].

\section{Posttraumatic stress disorder (PTSD)}

Activations of the trauma memories activate the same set of symptoms; the reason is particularly interesting and again these are the symptoms that we are talking about chest straight chest breathing up and down heart racing stress hormones the cortisol fight-or-flight adrenaline response stomach upset [39] heavy breathing turtle response freezing social avoidance decades of work by psychologists have identified that all of these symptoms are the sine qua non of panic symptoms but separately decades of work by neuroscientists have identified that it exact same set of symptoms in mice and men are the result of the hard-wired freer reflex of the amygdala specifically if you activate the amygdala chemically or electrically that leads to downstream brain activation of multiple regions that lead to IT [40] (Fig. 2).

\section{CONCLUSION}

Exact same set of symptoms, therefore, does not have to be confusing anymore what these symptoms are there specifically the primitive fear reflex activated by the amygdala $[41,42]$, and the question can then

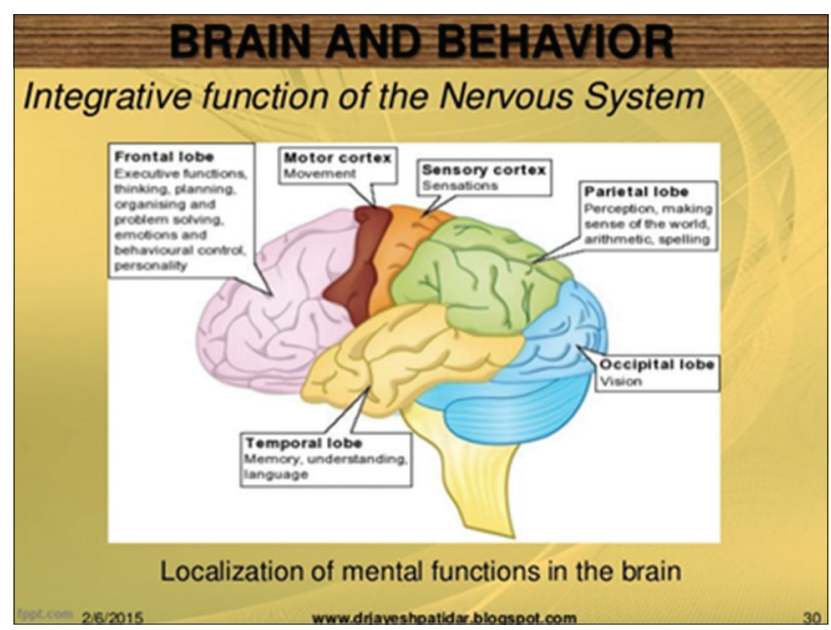

Fig. 2: Integrative function of the nervous system 
become what is different between those who have fear disorders and those who do not have why is the amygdala differentially activated in these people and what we focus on PTSD [43-45].

We generally think about PTSD as a disorder related to combat military that is where the name first came from but we now know that it occurs in times of terrorism, times of trauma interpersonal violence, motor vehicle accidents, and other experiences of life or death situations, why do some people following a severe trauma have high risk for PTSD [46], whereas others seem to be at low risk or after any severe experience or trauma one thing, we know that there seems to be a differential sensitivity, the amygdala comes to the time of the trauma with a different set of backgrounds a different biology [11]. Part of that genetic, we think that $30-40 \%$ of the differential risk for those who have PTSD and other fear-related disorders genetically mediated based on twin studies, we also know that a history of environmental stress and trauma can raise the stakes at the time of trauma exposure [12]. We know that how the learning event occurs, how many traumas one can differentially sensitize, the stress response and we also know that what happens in the aftermath of trauma [47]. The time at which new fear memory goes from being a labile state to a more permanent state is very important, we heard early about Alzheimer's disease and most of us think about learning and memory with relationship to explicit declarative new memories $[48,49]$ but it is important to know that there is a parallel memory system which is called as the emotional memory system and we form new memories through the emotional memory system and disorders of fear can be thought of as disorders of overlearning these fear memories so one example of differential stress response differential susceptibility. An example of nature and nurture or gene by environment interaction $[50,51]$.

\section{REFERENCES}

1. Adachi Y, Osada T, Sporns O, Watanabe T, Matsui T, Miyamoto K, et al. Functional connectivity between anatomically unconnected areas is shaped by collective network-level effects in the macaque cortex. Cereb Cortex 2012;22(7):1586-92.

2. Cavanagh JF, Shackman AJ. Frontal midline theta reflects anxiety and cognitive control: Meta-analytic evidence. J Physiol Paris 2015;109(1-3):3-15.

3. John YJ, Bullock D, Zikopoulos B, Barbas H. Anatomy and computational modeling of networks underlying cognitive-emotional interaction. Front Hum Neurosci 2013; 7:101.

4. Johnson JS, Kundu B, Casali AG, Postle BR. Task-dependent changes in cortical excitability and effective connectivity: A combined TMSEEG study. J Neurophysiol 2012;107(9):2383-92.

5. Kalanthroff E, Cohen N, Henik A. Stop feeling: Inhibition of emotional interference following stop-signal trials. Front Hum Neurosci 2013;7:78.

6. Lin T, Vaisvaser S, Fruchter E, Admon R, Wald I, Pine D, et al. A neurobehavioral account for individual differences in resilience to chronic military stress. Psychol Med 2014;45(5):1011-23.1-13.

7. Lindquist KA, Barrett LF. A functional architecture of the human brain: Emerging insights from the science of emotion. Trends Cogn Sci 2012;16(11):533-40.

8. Birn RM, Shackman AJ, Oler JA, Williams LE, Mcfarlin DR, Rogers GM, et al. Evolutionarily conserved prefrontal-amygdalar dysfunction in early-life anxiety. Mol Psychiatry 2014;19(8):915-22.

9. Moser JS, Moran TP, Schroder HS, Donnellan MB, Yeung N. On the relationship between anxiety and error monitoring: A meta-analysis and conceptual framework. Front Hum Neurosci 2013;7:466.

10. Admon R, Lubin G, Rosenblatt JD, Stern O, Kahn I, Assaf M, et al. Imbalanced neural responsivity to risk and reward indicates stress vulnerability in humans. Cereb Cortex 2012;23:28-35.

11. Bar-Haim Y, Lamy D, Pergamin L, Bakermans-Kranenburg MJ, van IJzendoorn $\mathrm{MH}$. Threat-related attentional bias in anxious and nonanxious individuals: A meta-analytic study. Psychol Bull 2007;133(1):1-24.

12. Barrett LF, Mesquita B, Ochsner KN, Gross JJ. The experience of emotion. Annu Rev Psychol 2007;58:373.

13. Berggren N, Derakshan N. Attentional control deficits in trait anxiety: Why you see them and why you don't. Biol Psychol 2013;92(3):440-6.

14. Holtmann J, Herbort MC, Wustenberg T, Soch J, Richter S, Walter H, et al. Trait anxiety modulates fronto-limbic processing of emotional interference in borderline personality disorder. Front Hum Neurosci 2013;7:54.

15. Hare TA, O'Doherty J, Camerer CF, Schultz W, Rangel A. Dissociating the role of the orbitofrontal cortex and the striatum in the computation of goal values and prediction errors. J Neurosci 2008;28:5623-30.

16. Murphy KP. Machine Learning: A Probabilistic Perspective. Cambridge, MA: MIT Press; 2012.

17. Shechner T, Britton JC, Perez-Edgar K, Bar-Haim Y, Ernst M, Fox NA, et al. Attention biases, anxiety, and development: Toward or away from threats or rewards? Depress Anxiety 2012;29(4):282-94.

18. Campbell DT, Fiske DW. Convergent and discriminant validation by the multitrait-multimethod matrix. Psychol Bull 1959;56(2):81-105.

19. Caspi A, Roberts BW, Shiner RL. Personality development: Stability and change. Annu Rev Psychol 2005;56:453-84.

20. Dolcos F, Denkova E. Current emotion research in cognitive neuroscience: Linking enhancing and impairing effects of emotion on cognition. Emot Rev 2014;6:362-75

21. Dreisbach G, Fischer R. The role of affect and reward in the conflicttriggered adjustment of cognitive control. Front Hum Neurosci 2012;6:342.

22. Gross JJ. Antecedent-and response-focused emotion regulation: Divergent consequences for experience, expression, and physiology. J Pers Soc Psychol 1998;74(1):224-37.

23. Gross JJ. The emerging field of emotion regulation: An integrative review. Rev Gen Psychol 1998;2(3):271.

24. Hare TA, Camerer CF, Rangel A. Self-control in decision-making involves modulation of the vmPFC valuation system. Science 2009;324(5927):646-8

25. Hartley CA, Phelps EA. Anxiety and decision-making. Biol Psychiatry 2012;72(2):113-8.

26. Heller AS, Lapate RC, Mayer KE, Davidson RJ. The face of negative affect: Trial-by-trial corrugator responses to negative pictures are positively associated with amygdala and negatively associated with ventromedial prefrontal cortex activity. J Cogn Neurosci 2014;26(9):2102-10.

27. Henderson HA, Pine DS, Fox NA. Behavioral inhibition and developmental risk: A dual-processing perspective. Neuropsychopharmacology 2014;40(1):207-24.

28. Hakamata Y, Lissek S, Bar-Haim Y, Britton JC, Fox NA, Leibenluft E, et al. Attention bias modification treatment: A meta-analysis toward the establishment of novel treatment for anxiety. Biol Psychiatry 2010;68(11):982-90.

29. Gilhotra N, Dhingra D. Neurochemical modulation of anxiety disorders. Int J Pharm Pharm Sci 2010;2 Suppl 1:1-6.

30. Shenhav A, Buckner RL. Neural correlates of dueling affective reactions to win-win choices. Proc Natl Acad Sci U S A 2014;111(30):10978-83.

31. Sheppes G, Levin Z. Emotion regulation choice: Selecting between cognitive regulation strategies to control emotion. Front Hum Neurosci 2013;7:179.

32. Siman-Tov T, Papo D, Gadoth N, Schonberg T, Mendelsohn A, Perry D, et al. Mind your left: Spatial bias in subcortical fear processing. J Cogn Neurosci 2009;21(9):1782-9.

33. Singer N, Eapen M, Grillon C, Ungerleider LG, Hendler T. Through the eyes of anxiety: Dissecting threat bias via emotional-binocular rivalry. Emotion 2012;12(5):960.

34. Southwick SM, Vythilingam M, Charney DS. The psychobiology of depression and resilience to stress: Implications for prevention and treatment. Annu Rev Clin Psychol 2005;1(1):255-91.

35. Shenhav A, Botvinick MM, Cohen JD. The expected value of control: An integrative theory of anterior cingulate cortex function. Neuron 2013;79(2):217-40.

36. Dreisbach G, Fischer R. The role of affect and reward in the conflicttriggered adjustment of cognitive control. Front Hum Neurosci 2012;6:342.

37. Honey CJ, Sporns O, Cammoun L, Gigandet X, Thiran JP, Meuli R, et al. Predicting human resting-state functional connectivity from structural connectivity. Proc Natl Acad Sci U S A 2009;106(6):2035-40.

38. Bhagat V, Jayaraj J, Haque M. Parent's self-efficacy, emotionality, and intellectual ability impacting the intervention of autism spectrum disorders: A review proposed model for appraisal of intervention. Int $\mathrm{J}$ Pharm Pharm Sci 2015;7(11):7-12.

39. Sreenivasan KK, Curtis CE, Desposito M. Revisiting the role of persistent neural activity during working memory. Trends Cogn Sci 2014;18(2):82-9.

40. Stollstorff M, Munakata Y, Jensen AP, Guild RM, Smolker HR, Devaney $\mathrm{JM}$, et al. Individual differences in emotion-cognition 
interactions: Emotional valence interacts with serotonin transporter genotype to influence brain systems involved in emotional reactivity and cognitive control. Front Hum Neurosci 2013;7:327.

41. Motzkin JC, Philippi CL, Wolf RC, Baskaya MK, Koenigs M. Ventromedial prefrontal cortex lesions alter neural and physiological correlates of anticipation. J Neurosci 2014;34(31):10430-7.

42. Pessoa L, Adolphs R. Emotion processing and the amygdala: From a 'low road' to "many roads" of evaluating biological significance. Nat Rev Neurosci 2010;11(11):773-83.

43. Ioannidis JP, Greenland S, Hlatky MA, Khoury MJ, Macleod MR, Moher $\mathrm{D}$, et al. Increasing value and reducing waste in research design, conduct, and analysis. Lancet 2014;383:166-75.

44. Ioannidis JP, Munafo MR, Fusar-Poli P, Nosek BA, David SP. Publication and other reporting biases in cognitive sciences: Detection, prevalence, and prevention. Trends Cogn Sci 2014;18(5):235-41.

45. Iordan AD, Dolcos S, Dolcos F. Neural signatures of the response to emotional distraction: A review of evidence from brain imaging investigations. Front Hum Neurosci 2013;7:200.

46. Lindström BR, Mattsson-Mårn IB, Golkar A, Olsson A. In your face: Risk of punishment enhances cognitive control and error-related activity in the corrugator supercilii muscle. PLoS One 2013;8(6):e65692.

47. Bishop SJ. Trait anxiety and impoverished prefrontal control of attention. Nat Neurosci 2009;12(1):92-8

48. Bishop SJ, Forster S. Trait anxiety, neuroticism and the brain basis of vulnerability to affective disorder. In: Armony J, Vuilleumier P, editors. The Cambridge Handbook of Human Affective Neuroscience. Cambridge: Cambridge University Press; 2013. p. 553-74.

49. Button KS, Ioannidis JP, Mokrysz C, Nosek BA, Flint J, Robinson ES, et al. Power failure: Why small sample size undermines the reliability of neuroscience. Nat Rev Neurosci 2013;14:365-76.

50. Damasio A. Human behaviour: Brain trust. Nature 2005;435(7042):571-2

51. Davis M, Whalen PJ. The amygdala: Vigilance and emotion. Mol Psychiatry 2001;6(1):13-34. 